\title{
Socio-economic and energy scenario development in Vietnam
}

\author{
T. T. Tran, M. Namazu \& Y. Matsuoka \\ Department of Urban and Environmental Engineering, \\ Kyoto University, Japan
}

\begin{abstract}
In supporting research on the socio-economic implication of energy policy, future scenarios are needed. Currently, most of the developing countries, especially in Southeast Asia, do not have specific targets for energy development rather than putting their main focus on economic growth. However, under natural constraints, especially energy resources, these countries must develop their own pathways in order to achieve socio-economic targets without compromising the environment and scarce natural resources. This paper provides the methodology to develop the platform of socio-economic and energy scenarios that includes two main steps. Firstly, the controversial parameters such as GDP and population are developed to be scale indices. Lately, the scale-based linear complement uses these scale indices to estimate the full-trend scenario for other parameters. The GAMS (General Algebraic Modelling System) programming is used in the processes of scale index development and scenario complement.

This study provides the social, economic, and energy platform for researchers and policy-makers in analyzing the implication of socio-economic development to energy consumption as well as the possible $\mathrm{CO}_{2}$ emissions, towards achieving sustainable development. Similarly to Vietnam, other developing countries may also face the lack of an energy database problem. Therefore, this study can be improved and expanded to those countries, especially in the Asian Pacific region. Keywords: scenario development, scale index, interpolation, compatibility analysis, information weighting, low carbon policy, sustainable development.
\end{abstract}




\section{Introduction}

Currently, there is no doubt that climate change has adverse impacts on the environment, society and economic activities of countries all over the world. Since 1997, 187 countries have signed and ratified the Kyoto Protocol with the main objective is to set up the Greenhouse Gases (GHGs) emissions limitation especially for developed countries. As a result, it helps to develop strategies for developing countries in achieving the sustainable development through Clean Development Mechanism (CDM), implemented in sectors such as energy, industry, transportation, agriculture, forestry, and waste management.

However, putting more efforts into the low GHGs emissions development might implicate the social and economic targets of a nation, particularly for those developing countries that have very low GHGs emissions but still put targets on energy security and minimizing emissions. The business of formulating energy policy depends heavily on questions of future energy demand (Slesser et al. [1]). Meanwhile, energy supply is so fundamental to the economy that a belief in future limitations would force us to consider new systems of production, of transport and even of government (Finon and Lapillonne [2]).

By developing scenarios, researchers will be able to analyze future determinants of energy requirements and compare them to supply availabilities, financing, environmental constraints, and other salient factors and driving forces in which, energy scenarios provide a framework for exploring future energy perspectives, including various combinations of technology options and their implications.

As a result, the socio-economic and energy scenario development may provide benchmarks for long-term policy making; therefore support policy makers better develop a flexible strategy, or at least to assess risk associated with an unpredictable future. Scenarios were and continue to be one of the main tools for dealing with the complexity and uncertainty of future challenges.

This paper is structured by reviewing the development targets of Vietnam in section 2. Section 3 explains the methodology applied for the scenario complement process and section 4 shows some complemented scenarios that are analyzed in this study. Section 5 is for the conclusion as well as some future research directions.

\section{Review of Vietnam future development targets}

According to the Vietnam Ministry of Planning and Investment, the national development strategy focuses on utilizing the growth factors in large, including employment, capital and land. In order to go ahead in a sustainable manner, a sharp qualitative step forward in depth must be generated, especially in terms of transforming the economic structure, upgrading the level of technology and management, both at macro and micro levels.

Vietnam targets that the production development should correspond to the market demand, strongly oriented to export, and at the same time oriented to an effective import substitution; as well as viewed to expand the domestic markets 
in order to improve the competitiveness and efficiency. The composition of exportable articles should be sharply moved from raw materials to afterprocessing products, of which there are more and more articles with recognized trademarks in the world market.

In urban areas and in industrial estates, stress is placed in the development processing industries with new no-pollution technologies. As for industrial products specified both for consumption and export, it is required to rapidly increase the domestic content and improve their competitiveness. Moreover, energy industry and selected industries producing capital goods and technical equipment for economic and defense purposes will be developed to effectively implement programs on infrastructure building.

In agriculture, the activities of agricultural extension and the application of new technologies, particularly biological technologies, should be promoted in order to improve both the productivity and the quality of products. Moreover, the Government also wants to ensure the macro-economic stability and make the nationals financial system healthy, both in terms of public finances and corporate finances, as well as people's financial situation.

The Vietnamese Government also ratified the "National target program on Energy Conservation and Efficiency" (Government of Socialist Republic of Vietnam [3]). This decision means targets are a matter of public announcement and encouragement, for science and technology, law and of regulation in order to timely implement activities on energy conservation and efficiency for the whole country. The objective is to reduce the investment for energy supply systems, bring benefits to the socio-economic, as well as protect the environment and effectively utilize the energy sources.

Besides the "Renewable Energy Development Policies," the Vietnamese Government also ratified the "Master plan to implement nuclear power application strategy for peaceful purposes towards 2020" (Government of Socialist Republic of Vietnam [4]), adopted the "Atomic Energy Law", established the "National Appraisal Committee for Construction of NPP". The desired target is to increase the contribution of renewable energy and nuclear power in the energy structure mix, up to $11 \%$ and $15-20 \%$, respectively.

\section{Methodology}

The method applied for this study is based on the scenarios information development system that researchers in Kyoto University are working on, both international and national scenarios (Tran et al. [5]). The general process of reference development for future socio-economic and energy simulation of Asian countries is mainly based on the data from national government. There are not so many references from national government providing data for future socioeconomic and energy scenarios, so we don't have much choice to consider, rather than combining data from available sources (from Office of Prime Minister, relevant ministries, etc.).

The process of developing the national reference scenario information includes some main steps: database compilation and scenario complement. 
Database is compiled from: (1) collected national statistics for historical data and from (2) reports of various organizations, both national and international to gain national future socioeconomic and energy/power development targets. These scatter scenarios are complemented for 50 years annually until 2050 by using scale-based interpolation.

Equations 1 and 2 are for the scale-based interpolation while the other equations are for the adjustment of target parameters based on the interpolated results. For the historical years (pre-2010), the value is adjusted into statistical data.

$$
\begin{aligned}
& \mathrm{Xo}_{\mathrm{t}}=\frac{\mathrm{TGT}_{-} \mathrm{org}_{\mathrm{t}}}{\mathrm{SCL}_{\mathrm{t}}} \\
& \text { Xo_itp } \mathrm{X}_{\mathrm{t}}=\mathrm{X} \mathrm{o}_{\mathrm{tmax}} \frac{\mathrm{t}-\mathrm{tmin}}{\mathrm{tmax}-\mathrm{tmin}} \times \mathrm{Xo}_{\mathrm{tmin}} \frac{\mathrm{tmax}-\mathrm{t}}{\mathrm{tmax}-\mathrm{tmin}}, \mathrm{tmin}<\mathrm{t}<\mathrm{tmax} \\
& \mathrm{Xref}_{\text {tref }}=\frac{\text { TGT_ref }_{\text {tref }}}{\text { SCL }_{\text {tref }}}
\end{aligned}
$$

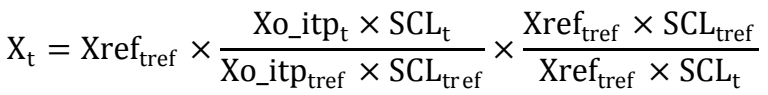

$$
\begin{aligned}
& \mathrm{TGT}_{\text {_comp }}=\mathrm{X}_{\mathrm{t}} \times \mathrm{SCL}_{\mathrm{t}}
\end{aligned}
$$

where; $t$ and ref calculated year and reference year

SCL scale index (GDP, population, GDP per capita)

TGT comp complemented target scenario

TGT_org original target scenario (described in the reference)

TGT_ref observed target parameter data

Xo ratio of target scenario and scale index

Xo_itp interpolated Xo

$\mathrm{X}$ adjusted $\mathrm{Xo}$

We assume that the population (projections from UN population prospects) will put influence on related indicators of employment, transport demand, and housing/building demand. Therefore, population will be used as scale index to estimate these parameters.

Meanwhile, Gross Domestic Product (GDP) is assumed as the driver of gross domestic product, import, and export. Each country might have different national targets of GDP growth rate achievement. Thus, this GDP (from GDP growth rate) will be used as scale index to estimate these parameters.

In the case of energy and energy consumption demand, these parameters are affected by both GDP and population. Therefore, the GDP-per-capita (GDPCAP) is used as scale for estimating these parameters.

The most difficult part of choosing the driving force is for energy potential and electricity generation. These parameters are affected by neither population nor GDP rather than rely mainly on the natural resource reservation of a nation. As a result, we assume that these parameters will be estimated based on the energy and power development plans of the country. 


\section{Analytical results}

\subsection{Population and employment}

Data for the total population of Vietnam is collected from the National Statistics Yearbook 2009 for the years before 2010. Some other national institutes also provide projections for population of Vietnam, but mainly up to the year 2030 (as illustrated in Figure 1). The trend of each reference is not so much different compared to the others. After the year 2030, the population growth rate is assumed to decrease due to the current population development policy of the Vietnamese Government. The total population for this period is also estimated based on the assumed growth rate. The population of Vietnam in 2050 is projected to be about 120mil., more than twice that of the year 2000 .

In terms of total employment, based on data from GSO (2009), it is estimated that each year, there are 1mil. jobs generated. This is consistent with the target of Vietnam employment development plan (8mil. jobs shall be generated in 2010). The total employment is projected to be about 90 mil. in 2050 , nearly 2.5 times that of the year 2000 .

The shares of employment in economic sectors strongly affect the contribution to GDP. Therefore, it would be large transfer from agriculture sector to industrial and service sectors, especially to services. It is estimated that each 5 -year period since $2015,2 \%$ and $3 \%$ of employment from agriculture will move to industry and services, respectively. This assumption is used to estimate the employment in agricultural, industrial and service sectors.

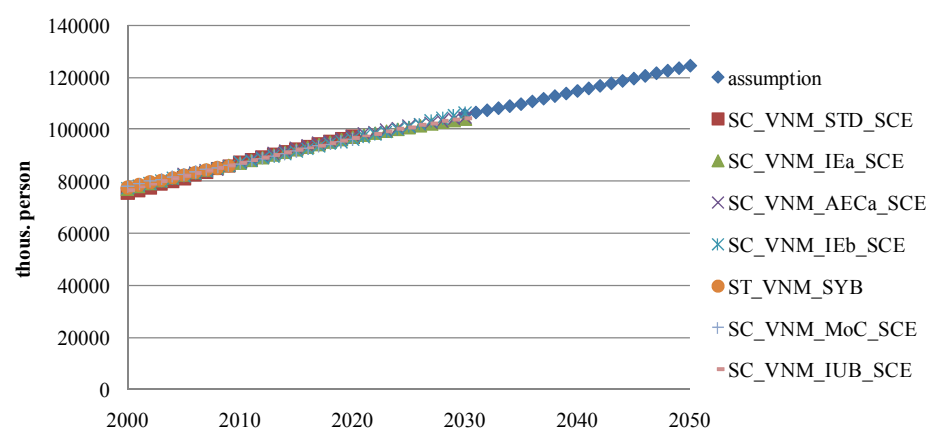

Figure 1: Total population scenarios of Vietnam.

\subsection{Economy}

The data for GDP is also collected from the statistical yearbook for historical data. Instead of having a projection for GDP, most of the references give targets for GDP growth rate and sectoral GDP contribution. We use these growth rate projections to assume the future GDP (see Figure 2). However, these growth rate scenarios are still very high compared to international projections. 


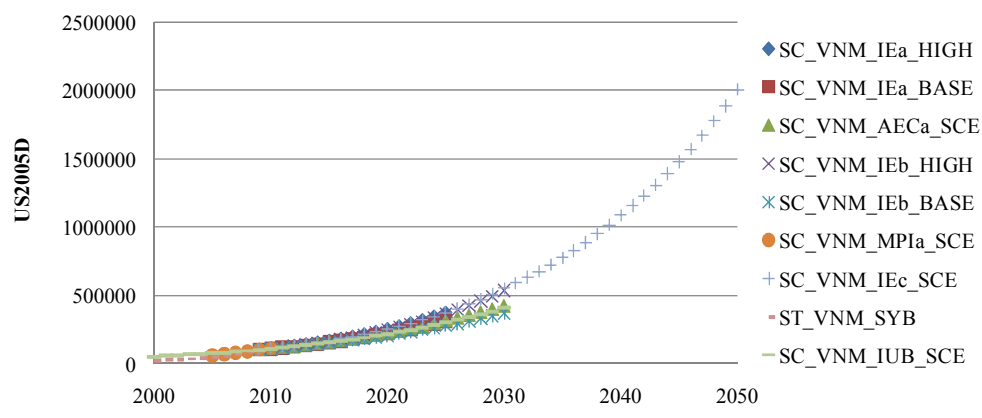

Figure 2: $\quad$ GDP scenarios of Vietnam.

Among the references, only the Institute of Energy (SC_VNM_IEc_SCE) provides total GDP projection for the years up to 2050, however, this is a very challenging projection that affects the contribution of economic sectors in the total GDP. Historical and projected data up to the year 2030 show similar contribution of industries and services to the GDP at a high level while that from agriculture is very low. According to the projection, the main contributor to GDP in the year 2050 would be commercial activities due to the governmental policy in investment on services.

\subsection{Transportation}

Currently we can only obtain the projection of transportation demand up to the year 2030 (Government of Socialist Republic of Vietnam [6]).

Passenger transportation demand is increasing in all transport modes, especially in road and aviation, in which road still dominates the total demand (as shown in Figure 3). The projection of the year 2030 is about 3.5 times compared to the year 2000. The freight transportation demand is also increasing

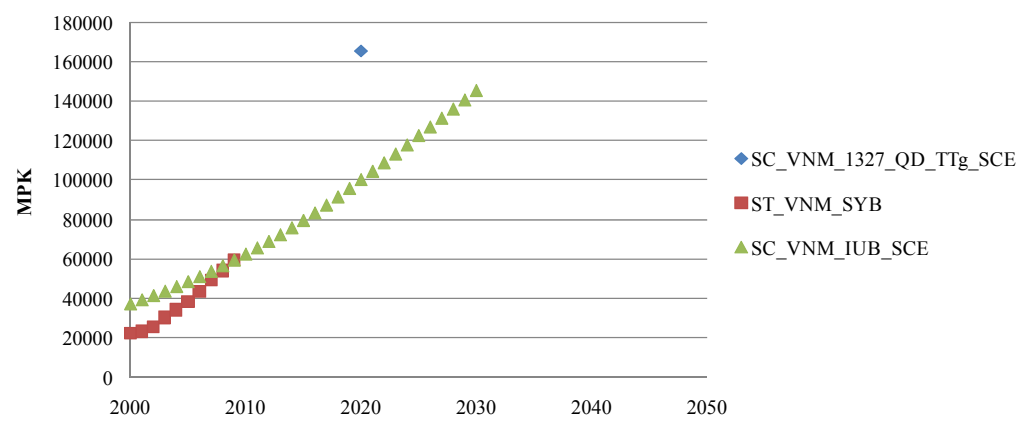

Figure 3: $\quad$ Passenger transportation volumes (mil. passenger-km). 
in which road and waterway modes are still dominated. The increase of freight transport is higher than that of passenger.

Increase of transportation demand, especially road transport as projected, may cause an increase in the consumption of petroleum products since they are main sources for road transportation in Vietnam.

\subsection{Energy consumption}

\subsubsection{Total final energy consumption by energy types}

Only projections up to the year 2030 are obtained for energy consumption since the Vietnam Government proposes a very general vision up to 2050 (Government of Socialist Republic of Vietnam [7]). Coal and oil final consumption still dominate the energy mix, followed by electricity consumption while natural gas consumption also increases the same as other energy types but still keeps a very small proportion (as illustrated in Figure 4).
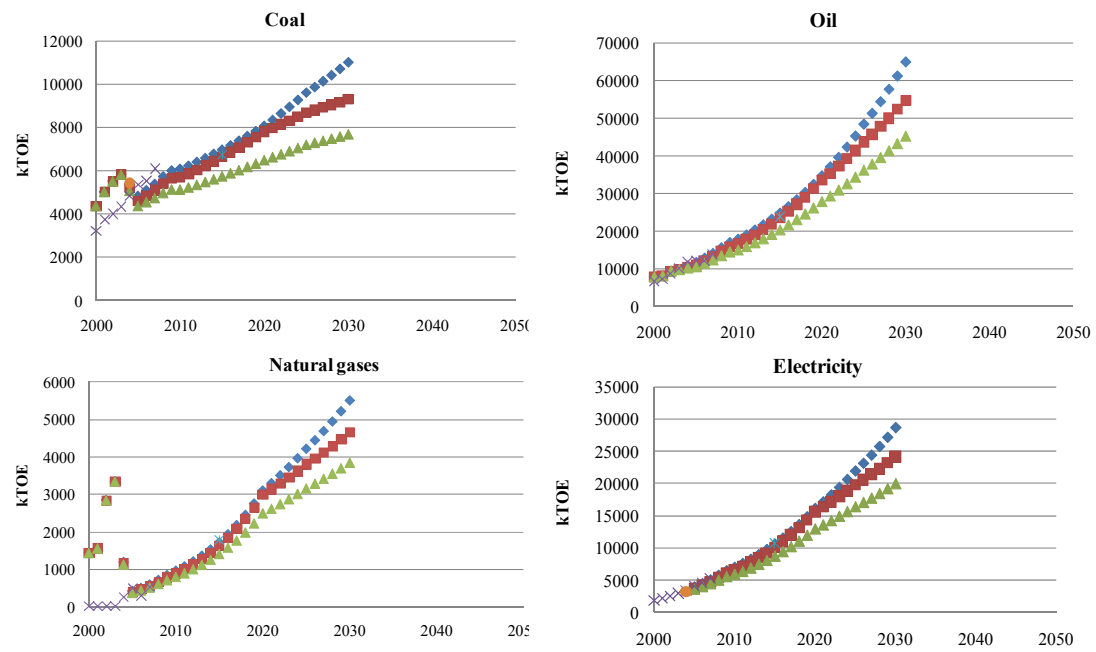

$$
\begin{array}{lll}
\bullet \text { SC_VNM_SAE_HIGH } & \square \text { SC_VNM_SAE_BASE } & \triangle \text { SC_VNM_SAE_LOW } \\
\times \text { SC_ADB_SCE } & * \text { SC_VNM_EPDb_SCE } & \text { OSC_VNM_MIT_SCE }
\end{array}
$$

Figure 4: Total final energy consumption by energy types.

\subsubsection{Total energy consumption by economic sectors}

According to Figure 5, industrial and transport sectors dominate energy consumption while agricultural and residential sectors have very small proportions. The service sector is projected to consume less than industrial and transport sectors, except one reference provides a very high projection for it. 

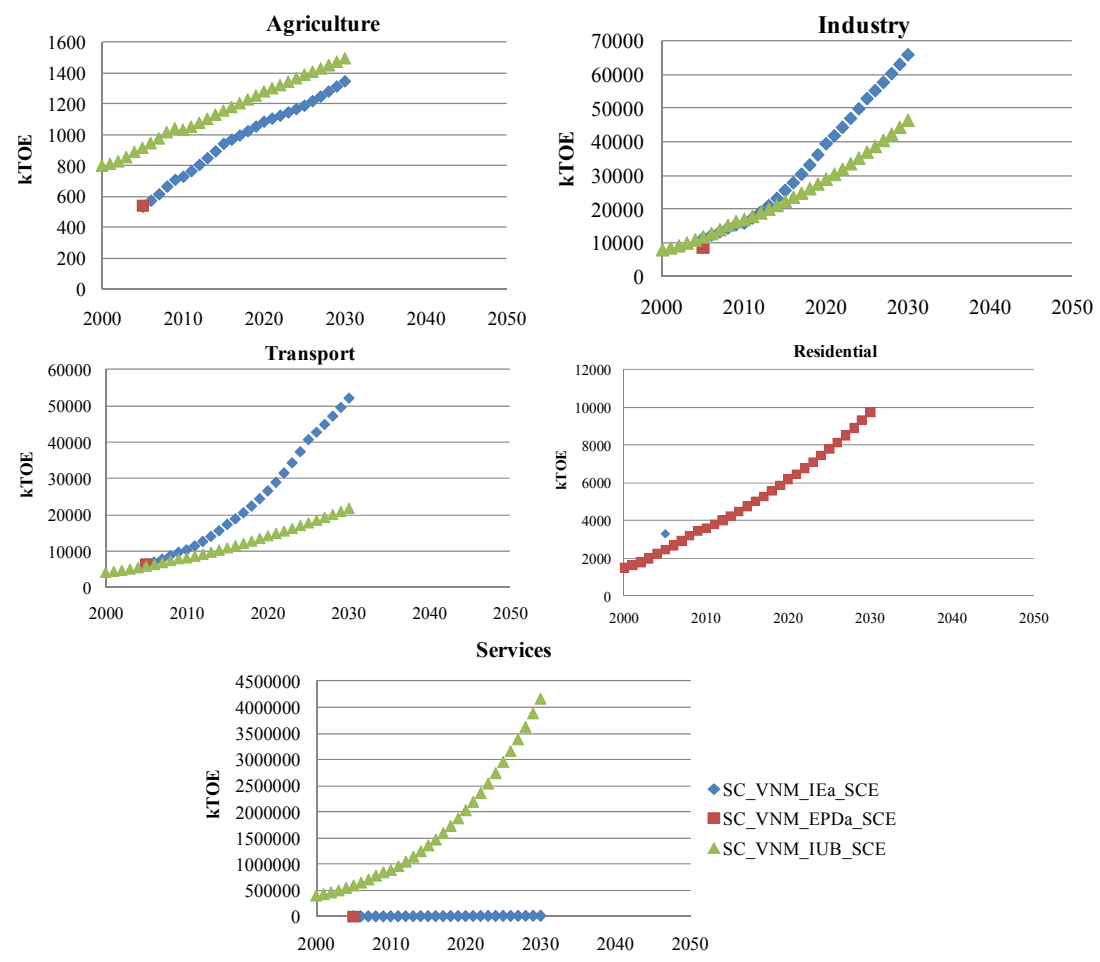

Figure 5: Total energy consumption by economic sectors.

\subsection{Energy reservation}

The traditional energy reservation is projected as shown in Figure 6. The total reservation may reach $120,000 \mathrm{kTOE}$ in the year 2030, twice that of the year 2005, according to the assumption from Vietnam Institute of Energy. While natural gases and coal reservation are projected to be increased, crude oil and biomass reservation seem to be maintained if not being reduced. This is one of the difficulties for research on the energy capacity in Vietnam since we cannot obtain particular information about the energy reservation.

In terms of energy development, the Vietnamese Government ratified the "National energy development strategy of Vietnam towards 2020 - vision to 2050" (1855/2007/QD-TTg). In this decision, the specific targets are listed in Table 1 .

The renewable energy (RE) reservation is collected from Institute of Energy [8], mainly available for some types of RE in Vietnam (Table 2) and the renewable energy contribution for power generation (Table 3).

Figure 7 shows the results of renewable energy reservation complemented in this study. The hydro power and geothermal are projected to be constant during 2020-2030 while photovoltaic (SPV) and wind power are estimated to be 
increased rapidly during the period. These complemented projections are based on some assumptions from Nguyen [9] for the contribution of renewable energy in energy supply.
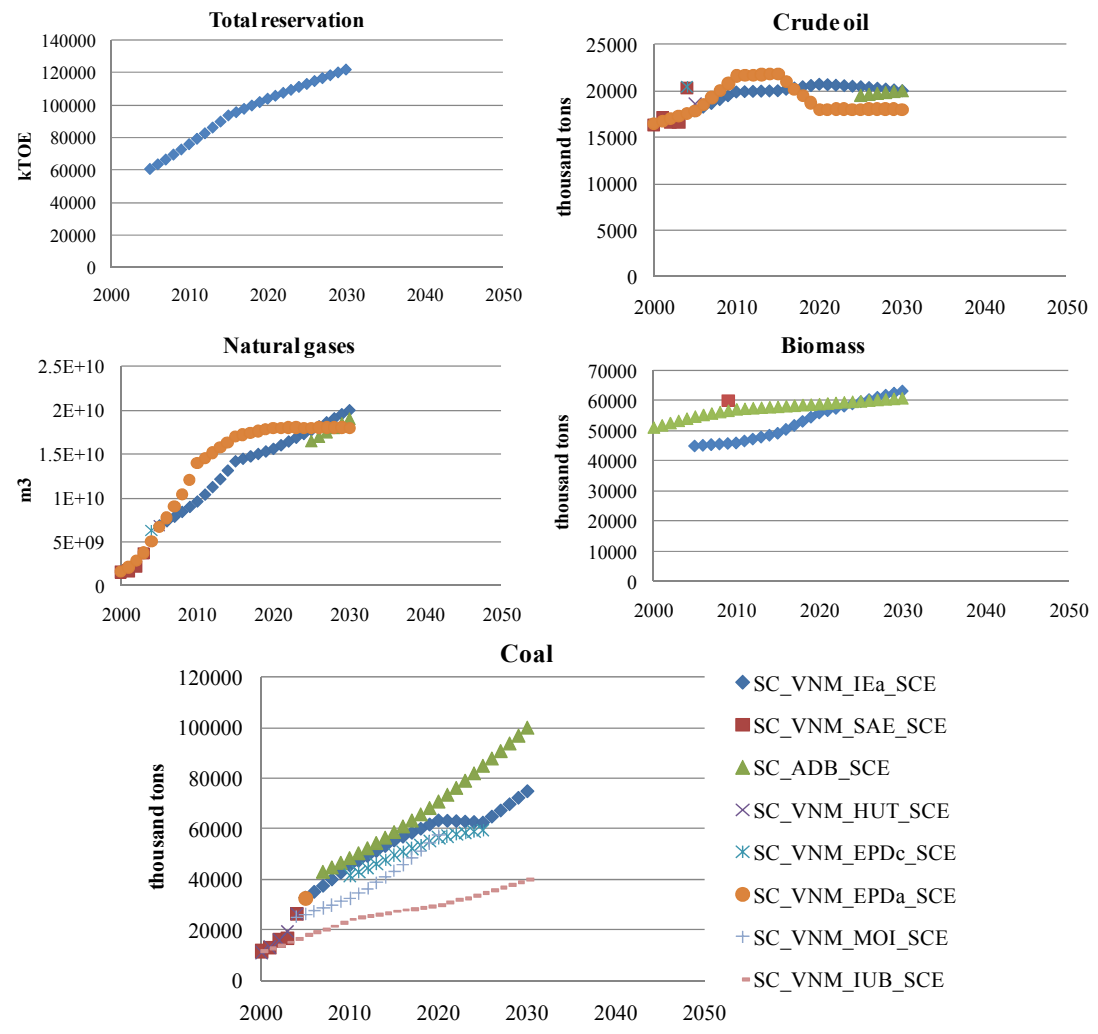

Figure 6: Traditional energy reservation.

Table 1: Vietnam energy development targets towards 2050.

\begin{tabular}{lccccc}
\hline \multicolumn{1}{c}{ Targets } & Unit & $\mathbf{2 0 1 0}$ & $\mathbf{2 0 2 0}$ & $\mathbf{2 0 2 5}$ & $\mathbf{2 0 5 0}$ \\
\hline Primary energy supply & Mil TOE & $47.5-49.5$ & $100-110$ & $110-120$ & $310-320$ \\
\hline Oil refinery plant (capacity) & Mil ton & & $25-30$ & & \\
\hline Oil gas reserve capacity & Days? & 45 & 60 & 90 & \\
\hline New and RE contribution & $\%$ total & 3 & 5 & & 11 \\
\hline Nuclear power & $\%$ total & & & & $15-20$ \\
\hline $\begin{array}{l}\text { Energy plan for rural/mountainous areas } \\
\text { Use commercial energy for cooking\% total } \\
\text { Electricity use }\end{array}$ & \% total & 90 & 80 & & \\
&
\end{tabular}


Table 2: $\quad$ Vietnam renewable energy potential by types.

\begin{tabular}{|c|c|c|}
\hline RE sorts & Potential & Note \\
\hline $\begin{array}{l}\text { Hydro } \\
\text { electricity }\end{array}$ & 120 bil. $\mathrm{kWh}$ & \\
\hline $\begin{array}{l}\text { Wind } \\
\text { power }\end{array}$ & $\begin{array}{c}1,300-2,900 \\
\mathrm{kWh} / \mathrm{sqm} / \mathrm{yr}\end{array}$ & $\begin{array}{l}\text { Islands: } 800-1,400 \\
\text { Coastal areas of central region: } 500-1,000 \\
\text { Highland and other regions: less than } 500\end{array}$ \\
\hline Biomass & $\begin{array}{c}\text { 43-46 } \\
\text { mil. TOE/yr }\end{array}$ & $\begin{array}{l}\text { Fuel wood: } 60 \% \text { (26-27 mil. TOE/yr) } \\
\text { Agricultural residues: } 40 \% \text { (17-19 mil. TOE/yr) }\end{array}$ \\
\hline Biogas & $\begin{array}{c}0.4 \\
\mathrm{mil} \mathrm{TOE} / \mathrm{yr}\end{array}$ & $\begin{array}{l}\text { Theoretical potential: } 0.4 \mathrm{mil} \mathrm{TOE} / \mathrm{yr} \\
\text { Exploitable: } 10 \%\end{array}$ \\
\hline Geothermal & $200 \mathrm{MW}$ & Concentrated in West (North and Central regions) \\
\hline Solar & $\begin{array}{l}43.9 \\
\text { bil. } \mathrm{TOE} / \mathrm{yr}\end{array}$ & $\begin{array}{l}\text { Theoretical potential: } 43.9 \mathrm{bil} . \mathrm{TOE} / \mathrm{yr} \\
\text { Average solar radiation: } 150 \mathrm{kcal} / \mathrm{sqm} / \mathrm{yr} \\
\text { Average radiation: } 200-2,500 \mathrm{hrs} / \mathrm{yr}\end{array}$ \\
\hline
\end{tabular}

Table 3: Renewable energy for power generation.

\begin{tabular}{|l|c|c|}
\hline \multicolumn{1}{|c|}{ Capacity structure } & $\mathbf{2 0 1 5}$ & $\mathbf{2 0 2 0}$ \\
\hline \multicolumn{1}{|c|}{ Total } & $\mathbf{4 2 , 4 7 0}$ MW & $\mathbf{6 0 , 6 0 0}$ MW \\
\hline Coal fired PPs & $12,100 \mathrm{MW}(28.5 \%)$ & $18,300 \mathrm{MW}(30.1 \%)$ \\
\hline Hydro PPs & $13,600 \mathrm{MW}(32 \%)$ & $17,200 \mathrm{MW}(28.3 \%)$ \\
\hline Oil and gas fired PPs & $13,400 \mathrm{MW}(31.6 \%)$ & $16,300 \mathrm{MW}(26.8 \%)$ \\
\hline Renewable generation & $1,270 \mathrm{MW}(4.9 \%)$ & $1,800 \mathrm{MW}(3 \%)$ \\
\hline Imported capacity (??) & $2,100 \mathrm{MW}(3 \%)$ & $5,200 \mathrm{MW}(8.6 \%)$ \\
\hline Nuclear PPs & - & $2,000 \mathrm{MW}(3.3 \%)$ \\
\hline
\end{tabular}
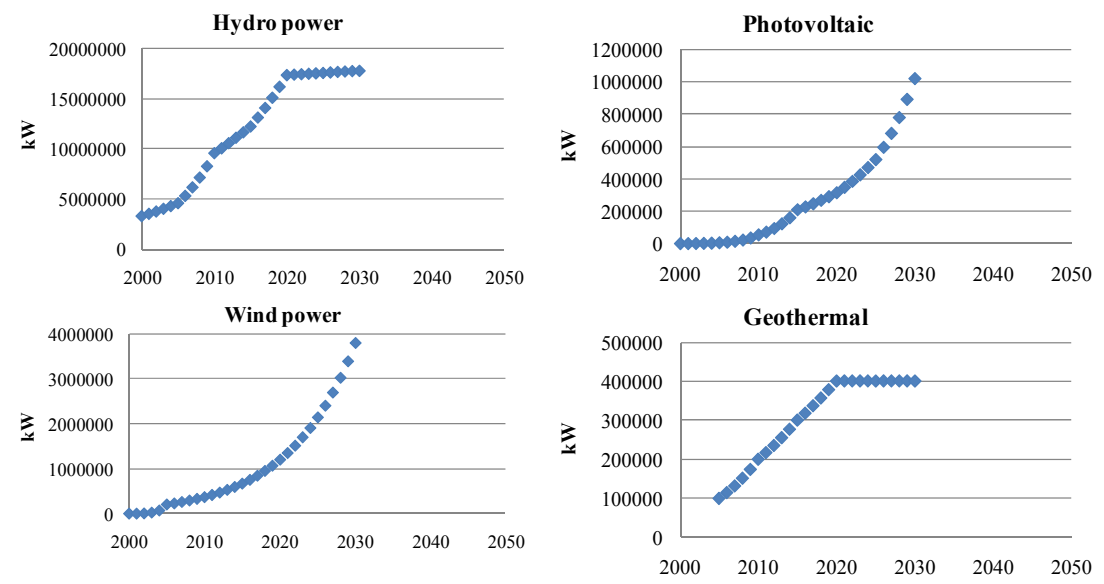

SC_VNM_IUB_SCE

Figure 7: Renewable energy reservation. 


\section{Conclusions}

The scenarios for major future direction of policies, particularly in what field the government/policy makers put more effort, for example, energy development or regional disparity, etc., are still unclear. Since the Computable General Equilibrium (CGE) model (Lofgren et al. [10]) is a strong tool to identify possible ranks of many alternatives proposed, the integration with scenario development will help to develop more tangible scenarios.

In this research, a very preliminary platform of socio-economic and energy scenarios of Vietnam has been developed to be used as input in CGE model to assess the feasibility of those future policies. Base on this principle, depends on the interest of audients/counterparts/policy makers, they can choose more concrete countermeasures/policies to develop their own socio-economic pathway and put into practical actions.

However, currently the reported scenarios are still unreliable and the complement methodology is simple to develop the preliminary platform of the Vietnam socio-economic and energy scenarios. The remained work is to develop more advanced method in order to provide more consistent projection for the future scenarios.

This study can be improved and expanded to those countries that have similar difficulties in developing the scenarios platform like Vietnam, especially other countries in the Asian Pacific region.

\section{References}

[1] Slesser, M., Bain, D. \& Hounam, I., Perspective for long-term energy policy. Futures, pp. 44-55, 1979.

[2] Finon, D. \& Lapillonne, B., Long term forecasting of energy demand in the developing countries. European Journal of Operational Research, 13, pp. 12-28, 1983.

[3] Government of Socialist Republic of Vietnam, National target program on Energy Conservation and Efficiency (79/2006/QD-TTg) (in Vietnamese), 2006.

[4] Government of Socialist Republic of Vietnam, Master plan to implement nuclear power application strategy for peaceful purposes towards 2020 (114/2007/QD-TTg) (in Vietnamese), 2007.

[5] Tran, T.T., Namazu, M. \& Matsuoka Y., National socio-economic and energy scenarios development, on-going research works, Department of Urban and Environmental Engineering, Kyoto University, Japan, 2010.

[6] Government of Socialist Republic of Vietnam, Transportation development strategy towards 2020 - vision to 2030 (35/2009/QD-TTg) (in Vietnamese), 2009.

[7] Government of Socialist Republic of Vietnam, National energy development strategy of Vietnam towards 2020 - vision to 2050 (1855/2007/QD-TTg) (in Vietnamese), 2007. 
264 Energy and Sustainability III

[8] Institute of Energy, Renewable Energy Development Policies (in Vietnamese), 2006.

[9] Nguyen, Q.K, Long term optimization of energy supply and demand in Vietnam with special reference to the potential of renewable energy, International University of Bremen, 2005.

[10] Lofgren, H., Harris, R. L. \& Robinson, S., A Standard Computable General Equilibrium (CGE) Model in GAMS: Spiral (Microcomputers in Policy Research 5), International Food Policy Research Institute, 2002. 